\title{
Differentiation of 3-O-Sulfated Heparin Disaccharide Isomers: Identification of Structural Aspects of the Heparin CCL2 Binding Motif
}

\author{
John K. Meissen, ${ }^{\mathrm{a}, \mathrm{b}}$ Matthew D. Sweeney, ${ }^{\mathrm{a}, \mathrm{b}, \mathrm{c}}$ Matthew Girardi, ${ }^{\mathrm{a}, \mathrm{b}, \mathrm{d}}$ \\ Roger Lawrence, ${ }^{\mathrm{e}}$ Jeffrey D. Esko, ${ }^{\mathrm{e}}$ and Julie A. Leary ${ }^{\mathrm{a}, \mathrm{b}}$ \\ ${ }^{a}$ Department of Molecular and Cellular Biology, University of California, Davis, California, USA \\ ${ }^{\mathrm{b}}$ Department of Chemistry, University of California, Davis, California, USA \\ ${ }^{\mathrm{c}}$ Novozymes, Inc., Davis, California, USA \\ ${ }^{\mathrm{d}}$ Department of Chemical Engineering, University of California, Davis, California, USA \\ ${ }^{\mathrm{e}}$ Department of Cellular and Molecular Medicine, Glycobiology Research and Training Center, University of \\ California, San Diego, La Jolla, California, USA
}

\begin{abstract}
The presence of 3-O-sulfated glucosamine residues in heparin or heparan sulfate plays a role in binding to antithrombin III and HSV infection. In this study, tandem mass spectrometry was used to differentiate between two heparin disaccharide isomers containing variable sulfate at $\mathrm{C} 6$ in a common disaccharide and $\mathrm{C} 3$ in a more rare one. The dissociation patterns shown by $\mathrm{MS}^{2}$ and $\mathrm{MS}^{3}$ were clearly distinguishable between the isomers, allowing their differentiation and quantitation. Using this technique, we show that an octasaccharide with 11 sulfate groups with high affinity for inflammatory chemokine CCL2 does not contain 3-O-sulfated disaccharides. (J Am Soc Mass Spectrom 2009, 20, 652-657) (C) 2009 Published by Elsevier Inc. on behalf of American Society for Mass Spectrometry
\end{abstract}

$\mathrm{H}$ eparin and heparan sulfate are glycosaminoglycans (GAGs) involved in a wide array of protein binding interactions. These interactions are implicated in a diverse group of biological processes such as viral invasion [1, 2], cell growth [3, 4], blood coagulation [5], and tumor metastasis [6-10]. Over a hundred different heparin binding proteins have been identified [11]. Initially, such protein interactions were believed to be relatively nonspecific. However, this perception has evolved to include selective protein binding, as research demonstrates specific GAG structural motifs can drastically alter protein binding affinity $[8,12,13]$. Despite the role of GAG structure in protein binding, exploration of specific GAG structural motifs governing protein binding remains greatly hampered due to lack of rapid and definitive means to ascertain GAG substitution patterns.

Heparin and heparan sulfate consist of a repeating disaccharide subunit containing either glucuronic acid or iduronic acid connected via a $\beta 1-4$ linkage to glucosamine. These GAGs possess significant structural diversity due to sugar stereochemistry and sulfation or acetylation at numerous positions within the repeating disaccharide subunit. The glucuronic acid and iduronic acid rings may display 2-O-sulfation, and the glucosamine

Address reprint requests to Dr. J. A. Leary, University of California, Davis, Department of Molecular and Cellular Biology, One Shields Road, Davis, CA 95616, USA. E-mail: jaleary@ucdavis.edu ring may have 6-O-sulfation or the rare 3-O-sulfation. Glucosamine may also have either sulfation or acetylation at the primary amine $[8,9]$. Sulfation and acetylation alone yield 24 possible substitution patterns.

Despite the rarity of 3-O-sulfation, this modification has been implicated in a number of biologically relevant pathways. Heparin binding to the serine protease inhibitor antithrombin III (ATIII) causes inhibition of two proteases, thrombin and factor $\mathrm{Xa}$, involved in blood clotting leading to an anticoagulant effect [14]. Binding depends on a particular pentasaccharide sequence responsible for binding ATIII containing a 3-O-sulfated glucosamine [15]. This 3-O-sulfate is a critical structural component of the ATIII binding sequence as removal results in a 1000-fold decrease in binding affinity [13]. HSV gD also binds a 3-O-sulfated sequence of heparan sulfate enabling viral entry into host cells $[2,16]$.

Researchers have employed numerous different methods to elucidate GAG structure as well as the pertinent GAG protein binding sequence. Methods include NMR, but this technique is difficult to apply due to relatively large material requirements [8]. Other methods include chromatography to identify disaccharide components $[17,18]$ and mass spectrometry combined with selective enzymatic digestion and desulfation [19-21]. Mass spectrometry is a particularly attractive method for structural analysis of GAGs because of minimal sample requirements and relatively fast data acquisition. Instruments capable of collision-induced dissociation
(C) 2009 Published by Elsevier Inc. on behalf of American Society for Mass Spectrometry. $1044-0305 / 09 / \$ 32.00$

doi:10.1016/j.jasms.2008.12.002
Published online December 9, 2008 Received October 27, 2008 Revised November 29, 2008 Accepted December 1, 2008 
(CID) provide an additional advantage as they possess the potential to disassociate GAG structures enabling identification of specific sulfation sites.

A class of proteins displaying GAG binding capacity are chemokines, small secreted proteins involved in numerous biological processes such as inflammation and development [22]. Research demonstrates that GAG/chemokine interaction can be required for proper in vivo function [23, 24]. Our laboratory identified selective chemokine ligand 2 (CCL2) binding of 11 sulfated heparin octasaccharide fragments [25]. This finding provides an opportunity to evaluate the role of 3-O-sulfation in a new GAG/protein interaction using mass spectrometry.

Herein, we report on the analysis of a known chemokine binding GAG octasaccharide [25], whose disaccharide composition has been determined and probed for 3-O-sulfation. Application of successive CID events generates cross-ring dissociation separating the primary amine, the 3-position, and the 6-position of glucosamine enabling definitive identification of the specific site of sulfation within a GAG disaccharide subunit. This method was applied to an 11-sulfated heparin octasaccharide obtained via hydrophobic trapping of CCL2/heparin complex to evaluate the role of 3-O-sulfation in the CCL2/heparin interaction.

\section{Experimental}

\section{Reagents and Instrumentation}

Heparin octasaccharide library was purchased from Dextra (Reading, UK). CarboPac PA1 ion-exchange column was purchased from Dionex (Sunnyvale, CA). High-pressure liquid chromatography (HPLC) grade solvents were purchased from Fisher Scientific (Santa Clara, CA). SAX HPLC was purchased from Waters Corporation (Milford, MA). Heparin desalting was performed using $1 \mathrm{kDa}$ Dispo-Biodialyzers (The Nest Group, Southborough, MA). Oasis HLB C18 column was purchased from Waters Corporation. Heparinase I, II, and III were purchased from Seikagaku Corporation (East Falmouth, MA). I-S and I-P disaccharide standards were purchased from Sigma-Aldrich (St. Louis, $\mathrm{MO})$. Disaccharide stock solutions were prepared at a concentrations of $2 \mathrm{mM}$ on the basis of their absorbance at $232 \mathrm{~nm}$ in $0.03 \mathrm{M} \mathrm{HCl} \varepsilon 232=5500 \mathrm{M}-1 \mathrm{~cm}-1$ ) [26].

Mass spectra for compositional analysis were obtained by using an ESI source on an LTQ MS (ThermoFinnigan, San Jose, CA). Disaccharides were sprayed at a concentration of $20 \mathrm{pmol} / \mu \mathrm{L}$ in a $1: 1 \mathrm{MeOH} / \mathrm{H}_{2} \mathrm{O}$ solution containing $10 \mathrm{mM} \mathrm{NH}_{4} \mathrm{OH}$ and $5 \mathrm{pmol} / \mu \mathrm{L}$ I-P internal standard. Samples were introduced by flow injection at $10 \mu \mathrm{L} / \mathrm{min}$ in 1:1 $\mathrm{MeOH} / \mathrm{H}_{2} \mathrm{O}$ using a syringe pump (Harvard Apparatus, Holliston, MA). Spectra were obtained in negative ion mode by using a spray voltage of $3.5 \mathrm{kV}$ and a capillary temperature of $220^{\circ} \mathrm{C}$ for all experiments. For $\mathrm{MS}^{2}$ experiments, a $3 \mathrm{~m} / \mathrm{z}$ isolation width was used for precursor ion selection at $m / z$ 191.4, and the ion was activated at $20 \%$ normalized collision energy for $100 \mathrm{~ms}$, and the qz value was maintained at 0.250. For $\mathrm{MS}^{3}$ experiments, a $3 \mathrm{Da}$ isolation width was used for precursor ion selection at $\mathrm{m} / \mathrm{z} 168.5$, and the ion was activated at $22 \%$ normalized collision energy for $100 \mathrm{~ms}$. Each mass spectrum obtained contains an average of 10 scans. Xcalibur, version 1.4 (ThermoFinnigan), was used for data acquisition and processing.

\section{Generation of 3-O-Sulfated Di- and Tetra-Saccharides}

A $\mathrm{CHO}$ cell line transduced with three copies of the human 3-OST-3A cDNA [27] were grown to confluence in $850 \mathrm{~cm}^{2}$ tissue culture roller bottles in Ham's F-12 medium containing $50 \mathrm{U} / \mathrm{mL}$ penicillin, $50 \mu \mathrm{g} / \mathrm{mL}$ streptomycin, $2 \mathrm{mM}$ glutamine, and 10\% fetal bovine serum. For cellular GAG extraction, cells were washed once in PBS and subjected to exhaustive digestion with Pronase (Sigma/Aldrich) in PBS at $37^{\circ} \mathrm{C}$ for $24 \mathrm{~h}$ followed by filtration through 0.22 micron cellulose acetate low protein binding membrane, anion-exchange chromatography with DEAE- sephacel (GE Healthcare, Chalfont St. Giles, UK) and ethanol precipitation as previously described [27]. The GAG chains were pelleted, washed with ice-cold $70 \%$ ethanol, re-pelleted, and dried. The GAG preparations were reconstituted in $100 \mu \mathrm{L}$ HS digest buffer ( $40 \mathrm{mM}$ ammonium acetate and $3.3 \mathrm{mM}$ calcium acetate, $\mathrm{pH} 7$ ) per roller bottle. Enzymatic depolymerization was carried out with $2 \mathrm{mU}$ each of heparin lyases I, II, and III per roller bottle and digested for $16 \mathrm{~h}$ at $37^{\circ} \mathrm{C}$. To determine the retention times for specific disaccharides, a small sample of the digest was analyzed on a C18 reverse phase column $(0.46 \mathrm{~cm} \times 25 \mathrm{~cm})($ Grace Davison Discovery Sciences, Deerfield, IL) connected to a LCQ classic quadrupole ion trap mass spectrometer equipped with an ESI source and a quaternary HPLC pump (Thermo-Finnigan). The isocratic steps were: $100 \%$ buffer A ( $8 \mathrm{mM}$ acetic acid, 5 $\mathrm{mM}$ dibutylamine) for $10 \mathrm{~min} ; 17 \%$ buffer B $(70 \%$ methanol, $8 \mathrm{mM}$ acetic acid, $5 \mathrm{mM}$ DBA) for $15 \mathrm{~min}$; $32 \%$ buffer B for $15 \mathrm{~min} ; 40 \%$ buffer B for $15 \mathrm{~min} ; 60 \%$ buffer B for $15 \mathrm{~min}$ and $100 \%$ buffer B for $10 \mathrm{~min}$. Eluted species were monitored in negative ion mode with the signal intensity optimized for D2S0, a representative disaccharide (GAG nomenclature described by Lawrence et al., 2008) [28]. The capillary temperature and spray voltage were kept at $140{ }^{\circ} \mathrm{C}$ and $4.75 \mathrm{kV}$, respectively. Peak assignments were based on several criteria including retention time, mass, and ion adduction [27]. Preparative amounts of heparan sulfate digests were loaded onto the column and the 3-O-sulfated species were collected at the expected retention times from the divert valve attached to the mass spectrometer. Purity was checked by LC/MS using the same criteria previously mentioned and disaccharide yield approximated by comparing extracted ion current for D2S3 and D2S9 
with that of a known amount of D2S6 run separately under the same conditions.

\section{Preparation of 11-Sulfated Heparin Octasaccharide}

Heparin octasaccharide containing 11 sulfates was isolated from the heparin octasaccharide library by using strong anion-exchange HPLC and a method similar to that described previously [29]. Approximately $400 \mu \mathrm{g}$ of an octasaccharide library was injected onto a CarboPac PA1 column and SAX HPLC was performed at a flow rate of $1 \mathrm{~mL} / \mathrm{min}$ using Solvent A (30 mM ammonium acetate, $\mathrm{pH} 3.5$ ) and Solvent B ( $3 \mathrm{M} \mathrm{NaCl}, 30 \mathrm{mM}$ ammonium acetate $\mathrm{pH}$ 3.5). A typical gradient consisted of: (1) 1-11 min, $0 \%$ $\mathrm{B}$, (2) $11-110 \mathrm{~min}, 0-100 \% \mathrm{~B}$, and (3) $111-120 \mathrm{~min}, 0 \%$ B. Chromatograms were recorded by monitoring the UV absorbance at $232 \mathrm{~nm}$. Fractions corresponding to the 11-sulfated octasaccharide were collected, lyophilized and extensively desalted by dialysis against water using $1 \mathrm{kDa}$ Dispo-Biodialyzers.

\section{Preparation of CCL2}

The CCL2 protein was expressed, purified, and processed as previously described [30]. Briefly, CCL2 was expressed using a codon-optimized construct in TAP302 cells. Soluble CCL2 was purified by ion-exchange chromatography followed by reverse-phase high-performance liquid chromatography (RP-HPLC). The N-terminal methionine was removed by aminopeptidase, leaving authentic human CCL2, which was then subjected to re-purification by RP-HPLC.

\section{CCL2 Affinity Enrichment of 11-Sulfated Octasaccharide}

Octasaccharide was enriched by incubating $40 \mu \mathrm{M}$ CCL2 with $200 \mu \mathrm{M}$ 11-sulfate octasaccharide in $100 \mu \mathrm{L}$ of $100 \mathrm{mM} \mathrm{NH}_{4} \mathrm{OAc}$ solution ( $\mathrm{pH}$ 6.8). The solution was applied to an Oasis solid-phase extraction (SPE) cartridge (Waters) that had been previously conditioned using $1 \mathrm{~mL}$ of methanol and then $1 \mathrm{~mL}$ of $\mathrm{H}_{2} \mathrm{O}$. The solid-phase SPE cartridge was flushed three times, each using $1 \mathrm{~mL} 200 \mathrm{mM} \mathrm{NH}_{4} \mathrm{OAc}$ solution ( $\mathrm{pH}$ 6.8) and then eluted by $1 \mathrm{~mL} 760 \mathrm{mM} \mathrm{NH}_{4} \mathrm{OAc}(\mathrm{pH}$ 6.8). The three washing fractions and the final elution faction were collected and desalted by dialyzing against water using a dialyzer with a molecular weight cutoff (MWCO) of $1 \mathrm{kDa}$.

\section{Compositional Analysis of Affinity Purified Heparin Octasaccharide}

Complete enzymatic digestion of heparin octasaccharide to constituent disaccharides was carried out with 5 $\mu \mathrm{g}$ heparin in $20 \mu \mathrm{L}$ of $20 \mathrm{mM}$ ammonium acetate buffer, $\mathrm{pH} 7.5,2 \mathrm{mM}$ calcium acetate, and 0.001 unit each of heparinase I, heparinase II, and heparinase III, incubated at $37^{\circ} \mathrm{C}$ for $16 \mathrm{~h}$ [20]. The reaction was quenched, yielding a final solution containing 20 $\mathrm{pmol} / \mu \mathrm{L}$ heparin disaccharide, $1: 1 \mathrm{MeOH} / \mathrm{H}_{2} \mathrm{O}, 5$ $\mathrm{pmol} / \mu \mathrm{L}$ internal standard I-P, and $10 \mathrm{mM}$ ammonium hydroxide. Samples were then analyzed using a combination of $\mathrm{MS}^{2}$ at $\mathrm{m} / \mathrm{z} 191.4$ and $\mathrm{MS}^{3}$ at 168.5 on an LTQ mass spectrometer.

\section{Results and Discussion}

Mass spectra were collected for both the D2S6 and the D2S3 disaccharide. As expected for positional isomers, the $\mathrm{MS}^{1}$ data for each of the disaccharides were virtually indistinguishable; in both cases the triply charged ion at $\mathrm{m} / \mathrm{z}$ 191.4, representing a molecular weight of $574.43 \mathrm{Da}$, was the principle ion detected (Supplementary Figure 1, which can be found in the electronic version of this article). These ions were isolated and studied utilizing tandem mass spectrometry via CID.

The MS ${ }^{2}$ data for the disaccharide isomers displayed different dissociation patterns and are clearly distinguishable (Figure 1). The D2S6 CID spectra (Figure 1a) was dominated by cross-ring cleavage yielding ion $\mathrm{A}$ at $\mathrm{m} / \mathrm{z}$ 218.0, and by a water loss ion at $\mathrm{m} / \mathrm{z} 185.3$ (Figure 1c) (dissociation nomenclature described by Domon and Costello, 1988) [31]. Dissociation also resulted in the formation of $\mathbf{X}, \mathbf{Y}$, and $\mathbf{B}$ ions. Ion $\mathbf{X}$, at $\mathrm{m} / \mathrm{z} 138.0$, is singly charged and results from a cross ring cleavage of the glucosamine residue, while ions $\mathrm{Y}$ and $\mathrm{B}$, at $\mathrm{m} / \mathrm{z}$ 168.5 and $\mathrm{m} / \mathrm{z}$ 127.0, respectively, are the glycosidic bond cleavage ions. The D2S3 CID spectra (Figure 1d) displayed greater diversity. The two major species resulted again from loss of water at $\mathrm{m} / \mathrm{z} 185.3$ and a $\mathrm{HSO}_{4}$ loss ion appearing at $\mathrm{m} / \mathrm{z} 238.5$. Additional abundant ions included a singly charged $\mathrm{HSO}_{4}$ at $m / z$ 97 and ion B with a water loss at $\mathrm{m} / \mathrm{z}$ 118.0. Trace amounts of ion A at $\mathrm{m} / \mathrm{z} 218.0$ were also detected, as well as other dissociation species annotated in Figure 1c.

While the $\mathrm{MS}^{2}$ data of the D2S6 and D2S3 disaccharides display clear differences in dissociation, and thus preliminary differentiation is possible, none of the observed fragments correspond to a cross ring cleavage separating the 6 and 3 positions of the glucosamine ring enabling definitive identification of the 3-O-sulfation site. It is most intriguing that one simple modification of 3-O versus 6-O-sulfation results in such drastically different spectra. This effect was also quite pronounced in earlier investigations of disaccharides carrying C-3 modifications $[32,33]$. Since both D2S3 and D2S6 produced the $\mathrm{Y}$ ion at $\mathrm{m} / \mathrm{z} 168.5$ in the $\mathrm{MS}^{2}$ data, corresponding to the glucosamine ring containing the structural variation, this ion was isolated and subjected to further dissociation in an $\mathrm{MS}^{3}$ experiment. Similar to the $\mathrm{MS}^{2}$ data, the $\mathrm{MS}^{3}$ data displayed differing dissociation patterns. The $\mathrm{MS}^{3}$ data of the D2S6 disaccharide (Figure $1 \mathrm{~b}$ ) revealed ion ${ }^{0,2} \mathrm{~A}$ at $\mathrm{m} / z 199.0$ and ion ${ }^{0,2} \mathrm{X}$ at $\mathrm{m} / \mathrm{z} 138.0$ with high abundance. The parent ion with water loss was also observed at $\mathrm{m} / \mathrm{z} 159.5$. Only trace 

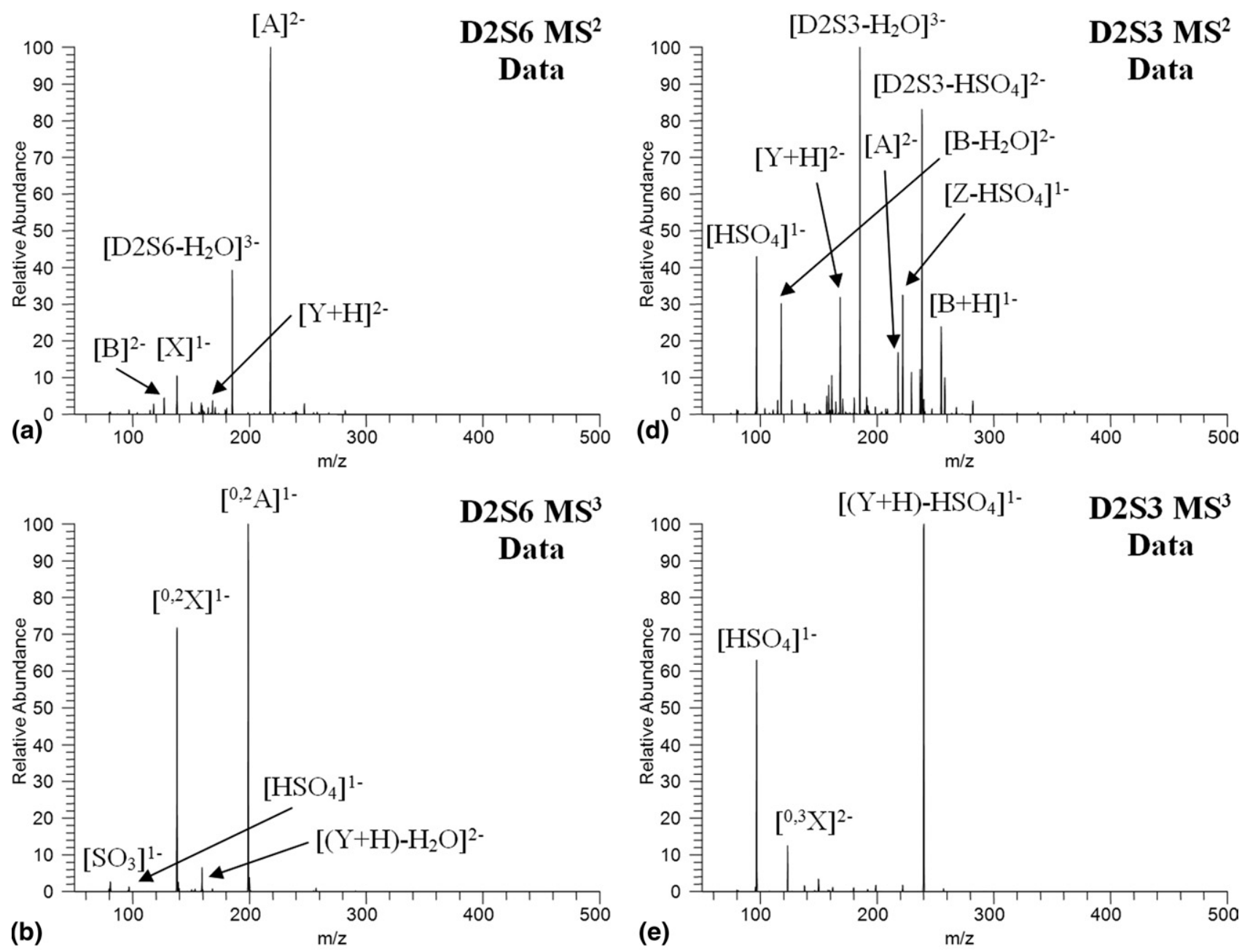

c)
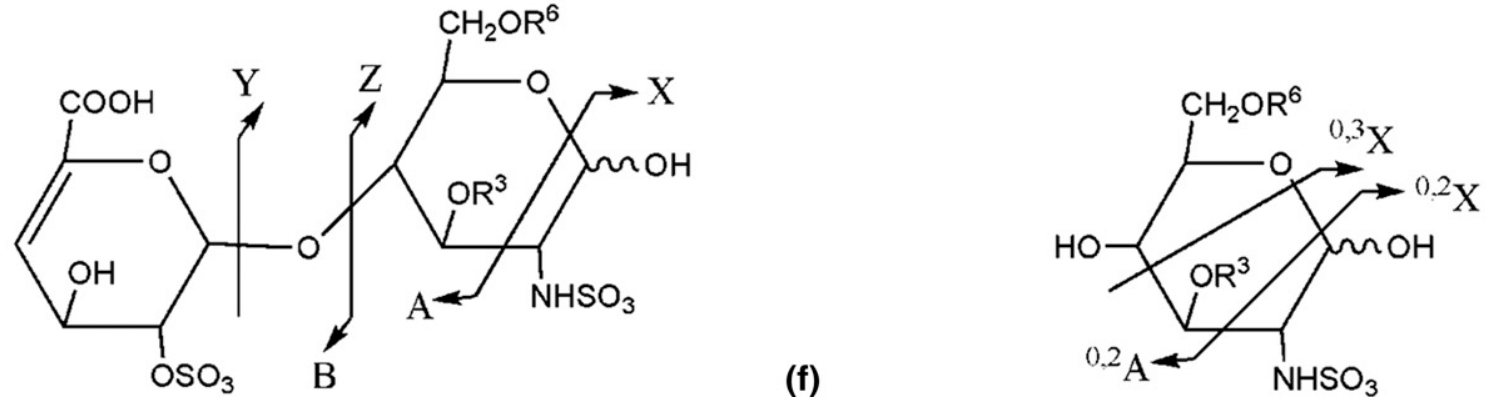

Figure 1. (a) D2S6 $\mathrm{MS}^{2}$ data, (b) D2S6 $\mathrm{MS}^{3}$ data, (c) cross ring and glycosidic cleavage pattern observed in $\mathrm{MS}^{2}$ dissociation, (d) D2S3 $\mathrm{MS}^{2}$ data, (e) D2S3 MS ${ }^{3}$ data, (f) cross ring cleavage pattern observed in $\mathrm{MS}^{3}$ dissociation.

$\mathrm{HSO}_{4}$ ions at $m / z 97.0$ and $\mathrm{SO}_{3}$ ions at $\mathrm{m} / \mathrm{z} 80.0$ were detected. The $\mathrm{MS}^{3}$ of the D2S3 disaccharide (Figure 1e) contained two major ions; the precursor ion with $\mathrm{HSO}_{4}$ loss at $m / z 240.0$ and the $\mathrm{HSO}_{4}$ ion at $m / z$ 97.0. The less abundant ${ }^{0,3} \mathrm{X}$ ion appears at $m / z$ 123.5. The ${ }^{0,3} \mathrm{X}$ ion corresponds to an ion containing an N-sulfate and a $3-\mathrm{O}$-sulfate, resulting from cross-ring cleavage separating the ${ }^{0,3} \mathrm{X}$ ion from the 6-position of the glucosamine ring.

The ${ }^{0,3} \mathrm{X}$ ion permits definitive identification of the D2S3 sulfation pattern in the $\mathrm{MS}^{3}$ data, and validates
CID as a rapid, effective tool to identify 3-O-sulfation in GAG disaccharide structures with minimal sample material. Interestingly, the D2S3 disaccharide standard also displayed a high abundance of $\mathrm{HSO}_{4}$ ions in contrast to the D2S6 disaccharide standard, suggesting the 3-O-sulfate is more labile than sulfates on other positions when the species undergo CID. Previously, our laboratory developed a quantitative method to determine GAG disaccharide composition [20] including all non-3-O-sulfated species. Identification of several diagnostic ions, such as $m / z 238.5$ in $\mathrm{MS}^{2}$ and $m / z$ 
240 in $\mathrm{MS}^{3}$, in D2S3 samples enables incorporation of this 3-O-sulfated species into existing mass spectrometry methodology for GAG quantitative compositional analysis [20].

This CID-based method was used to explore the possible involvement of 3-O-sulfation in the heparin/ CCL2 interaction. A fraction of 11-sulfated heparin octasaccharide, previously determined to bind to CCL2 [25], was obtained via strong anion exchange chromatography and incubated with CCL2 protein. The protein was bound to a hydrophobic trapping column, and an 11-sulfated heparin fraction enriched for CCL2 affinity was eluted from the column. This enriched eluent, and a control 11-sulfated heparin octasaccharide fraction, were enzymatically digested down to disaccharide constituents [29]. The sulfated disaccharide ion obtained at $m / z 191.4$ in the $\mathrm{MS}^{1}$ data were subjected to two successive rounds of CID to probe for the presence of 3-O-sulfation. The MS $^{2}$ and $\mathrm{MS}^{3}$ data (Table 1) obtained from both reaction mixtures were virtually identical to the $\mathrm{MS}^{2}$ and $\mathrm{MS}^{3}$ data obtained from the D2S6 disaccharide standard (Figure 2) asserting that the 3-sulfated disaccharide subunits possessed a D2S6 structure. The absence of numerous diagnostic ions observed in the D2S3 standard, such as $\mathrm{m} / \mathrm{z}$ 238.5 in the $\mathrm{MS}^{2}$ data, $\mathrm{m} / \mathrm{z} 240.0$ in the $\mathrm{MS}^{3}$ data, and the ${ }^{0,3} \mathrm{X}$ ion in the $\mathrm{MS}^{3}$ data, illustrate that the D2S3 structure was not present. The D0S9 disaccharide is not a possibility since all three sulfates reside in the reducing ring, and the mass of the prominent glycosidic bond cleavage ion clearly precludes this possibility. The D2H9 isomer is also eliminated since the mass of the A ion does not include the extra sulfate. Clearly, neither of these two isomers is present.

Several GAG/protein interactions depend on 3-Osulfation $[2,13,15,16]$. In contrast, our exploration of

Table 1. Ions observed in the $\mathrm{MS}^{2}$ and $\mathrm{MS}^{3}$ data

\begin{tabular}{|c|c|c|c|c|c|}
\hline \multicolumn{3}{|c|}{$\begin{array}{c}\mathrm{MS}^{2} \text { spectra of D2S6 } \\
\text { standard }\end{array}$} & \multicolumn{3}{|c|}{$\begin{array}{c}\mathrm{MS}^{3} \text { spectra of D2S6 } \\
\text { standard }\end{array}$} \\
\hline$m / z$ & Ion & Charge & $m / z$ & Ion & Charge \\
\hline 127.0 & $B$ & -2 & 80.0 & $\mathrm{SO}_{3}$ & -1 \\
\hline 138.0 & $x$ & -1 & 97.0 & $\mathrm{HSO}_{4}$ & -1 \\
\hline 168.5 & $\mathrm{Y}+\mathrm{H}$ & -2 & 138.0 & ${ }^{0,2} \mathrm{X}$ & -1 \\
\hline 185.3 & Parent- $\mathrm{H}_{2} \mathrm{O}$ & -3 & 159.5 & $(\mathrm{Y}+\mathrm{H})-\mathrm{H}_{2} \mathrm{O}$ & -2 \\
\hline 218.0 & A & -2 & 199.0 & ${ }^{0,2} \mathrm{~A}$ & -1 \\
\hline \multicolumn{3}{|c|}{$\begin{array}{c}\mathrm{MS}^{2} \text { spectra of D2S3 } \\
\text { standard }\end{array}$} & \multicolumn{3}{|c|}{$\begin{array}{c}\mathrm{MS}^{3} \text { spectra of D2S3 } \\
\text { standard }\end{array}$} \\
\hline$m / z$ & Ion & Charge & $m / z$ & Ion & Charge \\
\hline 97.0 & $\mathrm{HSO}_{4}$ & -1 & 97.0 & $\mathrm{HSO}_{4}$ & -1 \\
\hline 118.0 & B- $\mathrm{H}_{2} \mathrm{O}$ & -2 & 123.5 & ${ }^{0,3} x^{4}$ & -2 \\
\hline 168.5 & $\mathrm{Y}+\mathrm{H}$ & -2 & 240.0 & $(\mathrm{Y}+\mathrm{H})-\mathrm{HSO}_{4}$ & -1 \\
\hline 185.3 & Parent- $\mathrm{H}_{2} \mathrm{O}$ & -3 & & & \\
\hline 218.0 & A & -2 & & & \\
\hline 222.0 & $\mathrm{Z}-\mathrm{HSO}_{4}-\mathrm{H}$ & -1 & & & \\
\hline 238.5 & Parent- $\mathrm{HSO}_{4}$ & -2 & & & \\
\hline 255.0 & $B+H$ & -1 & & & \\
\hline
\end{tabular}
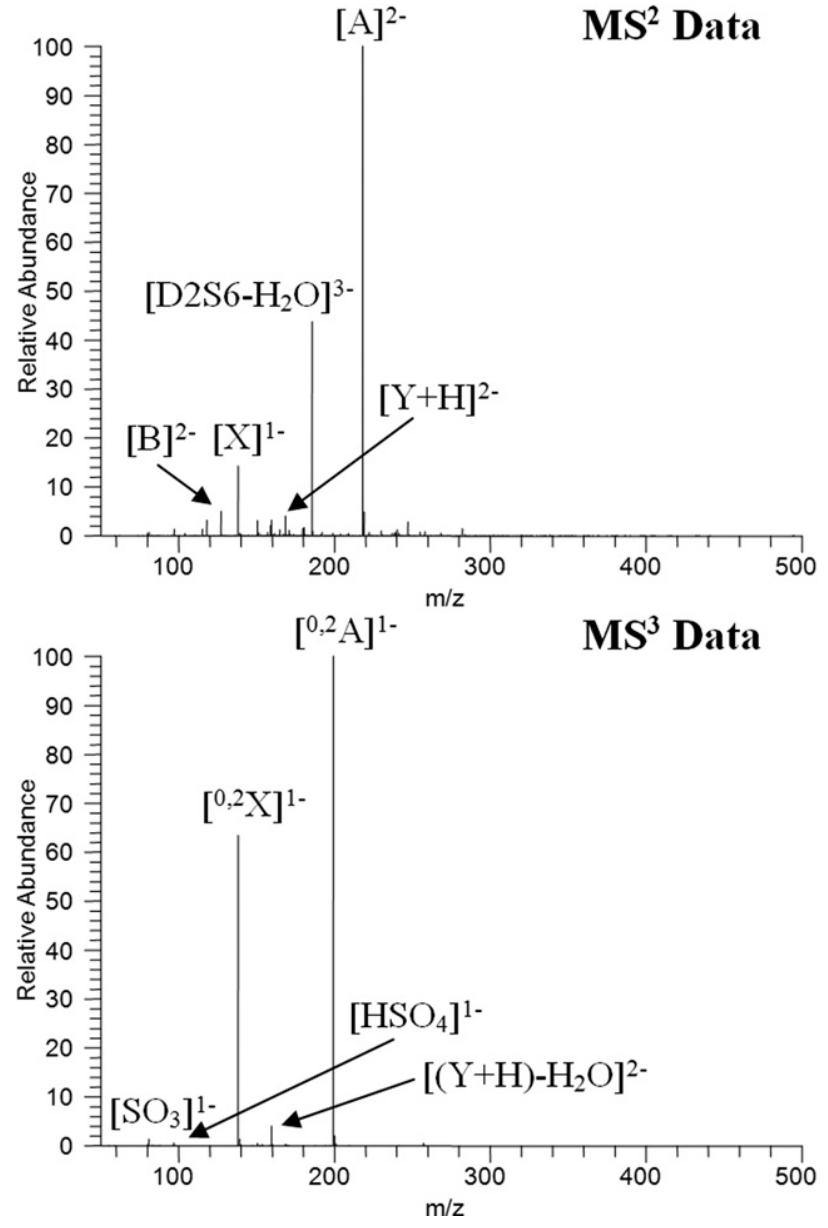

Figure 2. Spectra of CCL2 affinity enriched 11-sulfated heparin fraction showing same product ions as observed for the D2S6 isomer (a) $\mathrm{MS}^{2}$ data, (b) $\mathrm{MS}^{3}$ data.

the heparin/CCL2 interaction, using mass spectrometry combined with CID, did not reveal measurable levels of 3-O-sulfate containing species, suggesting that 3-Osulfation may not be involved in chemotactic GAG/ protein interactions. Subsequently, while 3-O-sulfation may be crucial for certain interactions, its function could be limited to specific GAG/protein complexes instead of playing a more universal role in chemotaxis or protein binding.

\section{Conclusions}

We have utilized a mass spectrometry method using CID to create cross-ring cleavage events separating the numerous potential sulfation positions within the disaccharide subunit structure. This method allows for robust, rapid detection and identification of individual 3-O-sulfate containing heparin structures, such as D2S3, within a heterogeneous disaccharide mixture via identification of specific diagnostic ions. Exploration of GAG/protein interaction has been greatly hampered due to lack of effective means to investigate GAG structure, and this tool presents a means to improve our 
understanding of the relationship between GAG structure and protein binding affinity for individual GAG/ protein interactions.

This method was used to probe the possible role of 3-O-sulfation in the CCL2/GAG interaction, from a heparin library. An 11-sulfated heparin octasaccharide enriched for CCL2 binding affinity did not reveal the presence 3-O-sulfation at a detectable level, suggesting 3-O-sulfation is not a prominent factor governing CCL2/GAG binding.

\section{Acknowledgments}

JDE wishes to thank the National Institute of Health (GM33063) and JAL gratefully acknowledges GM47356 for financial support.

\section{References}

1. Chen, Y.; Maguire, T.; Hileman, R. E.; Fromm, J. R.; Esko, J. D.; Linhardt, R. J.; Marks, R. M. Dengue Virus Infectivity Depends on Envelope Protein Binding to Target Cell Heparan Sulfate. Nat. Med. 1997, 3, 866-871.

2. Shukla, D.; Liu, J.; Blaiklock, P.; Shworak, N. W.; Bai, X.; Esko, J. D. Cohen, G. H.; Eisenberg, R. J.; Rosenberg, R. D.; Spear, P. G. A Novel Role for 3-O-Sulfated Heparan Sulfate in Herpes Simplex Virus 1 Entry. Cell 1999, 99, 13-22.

3. Castellot, J. J.; Hoover, R. L.; Harper, P. A.; Karnovsky, M. J. Heparin and Glomerular Epithelial Cell-Secreted Heparin-Like Species Inhibit Mesangial-Cell Proliferation. Am. J. Pathol. 1985, 120, 427-435.

4. Perrimon, N.; Bernfield, M. Specificities of Heparan Sulphate Proteoglycans in Developmental Processes. Nature 2000, 404, 725-728.

5. Marcum, J. A.; McKenney, J. B.; Galli, S. J.; Jackman, R. W.; Rosenberg, R. D. Anticoagulantly Active Heparin-Like Molecules from Mast CellDeficient Mice. Am. J. Physio. 1986, 250, H879-H888.

6. Vlodavsky, I.; Friedmann, Y.; Elkin, M.; Aingorn, H.; Atzmon, R.; Ishai-Michaeli, R.; Bitan, M.; Pappo, O.; Peretz, T.; Michal, I.; Spector, L.; Pecker, I. Mammalian Heparanase: Gene Cloning, Expression, and Function in Tumor Progression and Metastasis. Nat. Med. 1999, 5, 793-802.

7. Hulett, M. D.; Freeman, C.; Hamdorf, B. J.; Baker, R. T.; Harris, M. J.; Parish, C.R. Cloning of Mammalian Heparanase, an Important Enzyme in Tumor Invasion and Metastasis. Nat. Med. 1999, 5, 803-809.

8. Rabenstein, D. L. Heparin and Heparan Sulfate: Structure and Function. Nat. Prod. Reports 2002, 19, 312-331.

9. Bishop, J. R.; Schuksz, M.; Esko, J. D. Heparan Sulphate Proteoglycans Fine-Tune Mammalian Physiology. Nature 2007, 446, 1030-1037.

10. Esko, J. D.; Selleck, S. B. Order out of Chaos: Assembly of Ligand Binding Sites in Heparan Sulfate. Annu. Rev. Biochem. 2002, 71, 435-471.

11. Conrad, H. E. Heparin-Binding Proteins; Academic Press: San Diego, CA, 1998; pp. 1-5 183-202.

12. Lindahl, U.; Kusche-Gullberg, M.; Kjellén, L. Regulated Diversity of Heparan Sulfate. J. Biol. Chem. 1998, 273, 24979-24982.

13. Atha, D. H.; Lormeau, J. C.; Petitou, M.; Rosenberg, R. D.; Choay, J. Contribution of Monosaccharide Residues in Heparin Binding to Antithrombin Iii. Biochemistry 1985, 24, 6723-6729.

14. de Kort, M.; Buijsman, R. C.; van Boeckel, C. A. Synthetic Heparin Derivatives as New Anticoagulant Drugs. Drug Discov. Today 2005, 10, 769-779.
15. Petitou, M.; Casu, B.; Lindahl, U. 1976-1983, a Critical Period in the History of Heparin: The Discovery of the Antithrombin Binding Site. Biochimie 2003, 85, 83-89.

16. Tiwari, V.; Clement, C.; Xu, D.; Valyi-Nagy, T.; Yue, B. Y.; Liu, J.; Shukla, D. Role for 3-O-Sulfated Heparan Sulfate as the Receptor for Herpes Simplex Virus Type 1 Entry into Primary Human Corneal Fibroblasts. J. Virol. 2006, 80, 8970-8980.

17. Chen, J.; Liu, J. Characterization of the Structure of AntithrombinBinding Heparan Sulfate Generated by Heparan Sulfate 3-OSulfotransferase 5. Biochim. Biophys. Acta 2005, 1725, 190-200.

18. Liu, J.; Shriver, Z.; Blaiklock, P.; Yoshida, K.; Sasisekharan, R.; Rosenberg, R. D. Heparan Sulfate D-Glucosaminyl 3-O-Sulfotransferase-3a Sulfates N-Unsubstituted Glucosamine Residues. J. Biol. Chem. 1999, $274,38155-38162$.

19. Venkataraman, G.; Shriver, Z.; Raman, R.; Sasisekharan, R. Sequencing Complex Polysaccharides. Science 1999, 286, 537-542.

20. Saad, O. M.; Leary, J. A. Compositional Analysis and Quantification of Heparin and Heparan Sulfate by Electrospray Ionization Ion Trap Mass Spectrometry. Anal. Chem. 2003, 75, 2985-2995.

21. Saad, O. M.; Ebel, H.; Uchimura, K.; Rosen, S.D.; Bertozzi, C. R.; Leary, J. A. Compositional Profiling of Heparin/Heparan Sulfate Using Mass Spectrometry: Assay for Specificity of a Novel Extracellular Human Endosulfatase. Glycobiology 2005, 15, 818-826.

22. Rossi, D.; Zlotnik, A. The Biology of Chemokines and Their Receptors. Ann. Rev. Immunol. 2000, 18, 217-242.

23. Proudfoot, A. E.; Handel, T. M.; Johnson, Z.; Lau, E. K.; LiWang, P. Clark-Lewis, I.; Borlat, F.; Wells, T. N.; Kosco-Vilbois, M. H. Glycosaminoglycan Binding and Oligomerization are Essential for the In Vivo Activity of Certain Chemokines. Proc. Natl. Acad. Sci. U.S.A. 2003, 100, 1885-1890.

24. Johnson, Z.; Kosco-Vilbois, M. H.; Herren, S.; Cirillo, R.; Muzio, V.; Zaratin, P.; Carbonatto, M.; Mack, M.; Smailbegovic, A.; Rose, M.; Lever R.; Page, C.; Wells, T. N.; Proudfoot, A. E. Interference with Heparin Binding and Oligomerization Creates a Novel Anti-Inflammatory Strategy Targeting the Chemokine System. J. Immunol. 2004, 137, 5776-5785.

25. Yu, Y.; Sweeney, M. D.; Saad, O. M.; Crown, S. E.; Hsu, A. R.; Handel T. M.; Leary, J. A. Chemokine-Glycosaminoglycan Binding: Specificity for Ccr2 Ligand Binding to Highly Sulfated Oligosaccharides Using FTICR Mass Spectrometry. J. Biol. Chem. 2005, 280, 32200-32208.

26. Desai, U. R.; Wang, H. M.; Linhardt, R. J. Specificity Studies on the Heparin Lyases from Flavobacterium Heparinum. Biochemistry 1993, 32, $8140-8145$

27. Lawrence, R.; Kuberan, B.; Lech, M.; Beeler, D. L.; Rosenberg, R. D. Mapping Critical Biological Motifs and Biosynthetic Pathways of Heparan Sulfate. Glycobiology 2004, 14, 467-479.

28. Lawrence, R.; Lu, H.; Rosenberg, R. D.; Esko, J. D.; Zhang, L. Disaccharide Structure Code for the Easy Representation of Constituent Oligosaccharides from Glycosaminoglycans. Nat. Methods 2008, 5, 291-292.

29. Sweeney, M. D.; Yu, Y.; Leary, J. A. Effects of Sulfate Position on Heparin Octasaccharide Binding to $\mathrm{Ccl} 2$ Examined by Tandem Mass Spectrometry. J. Am. Soc. Mass Spectrom. 2006, 17, 1114-1119.

30. Paavola, C. D.; Hemmerich, S.; Grunberger, D.; Polsky, I.; Bloom, A. Freedman, R.; Mulkins, M.; Bhakta, S.; McCarley, D.; Wiesent, L.; Wong B.; Jarnagin, K.; Handel, T. M. Monomeric Monocyte Chemoattractant Protein-1 (Mcp-1) Binds and Activates the Mcp-1 Receptor Ccr2b. J. Biol. Chem. 1998, 273, 33157-33165.

31. Domon, B.; Costello, C. E. A Systematic Nomenclature for Carbohydrate Fragmentations in Fab-MS/MS Spectra of Glycoconjugates. Glycoconjugate J. 1988, 5, 397-409.

32. Staempfli, A.; Zhou, Z.; Leary, J. A. Gas-Phase Dissociation Mechanisms of Dilithiated Disaccharides: Tandem Mass Spectrometry and Semiempirical Calculations. J. Org. Chem. 1992, 57, 3590-3594.

33. Leary, J. A.; Zhou, Z.; Ogden, S.; Williams, T. D. Gas Phase Investigation of Lithiated Peptide Adducts: Tandem Mass Spectrometry and Semiempirical Studies. J. Am. Soc. Mass Spectrom. 1990, 1, 473-480. 